\title{
Analysis of D-Dimer Levels among Covid -19 Positive Patients in a Tertiary Care Hospital in Bangalore
}

\author{
Manasa S. ${ }^{1 *}$, Vikram. H. C V. ${ }^{2}$
}

DOI: https://doi.org/10.17511/ijmrr.2021.i02.05

1* Manasa S, Microbiologist, Sagar hospital, Bangalore, Karnataka, India.

2 Venkatesh Vikram. H. C, Medical Director, Sagar hospital, Bangalore, Karnataka, India.

Introduction: Pro-thrombotic changes are stimulated by Corona Virus as it has an affinity for endothelium and lung structures and this may explain its association with thrombotic events, reduction of pulmonary gas exchange, respiratory distress, and death. D-dimer is a specific marker of the breakdown of a fibrin clot and has been used as a diagnostic and prognostic marker in VTE and other coagulation disorders. Objectives: The objective of this study was to assess the correlation of the D-Dimer levels and disease severity among COVID-19 patients. Materials and methods: This is a retrospective study done over 6 months from July 2020 to December 2020 in a tertiary care hospital in Bangalore. All the COVID- 19 positive cases who were admitted to our hospital were audited regarding the D-dimer levels during admission and the course of the treatment. Results: Coagulation disorder occurred at the early stage of COVID-19 infection, with 1066 (57.7\%) patients having increased D-dimer levels. Out of 1846 COVID 19 patients 106 (5.7\%)patients died due to complications. 106 patients who deceased, all the patients had an increased $\mathrm{D}$ dimer value either in the first lab test or in the consecutive tests. Among 106 patients $56(52.8 \%)$ patients had increased D-dimer at the first lab test, $32(30.1 \%)$ had D-dimer increased at the second and $18(16.98 \%)$ in third lab tests. The increased D-dimer levels were closely associated with the progression of the disease and also the changes in the CT imaging. Conclusion: The increase in D-Dimer levels also increased the complications in the COVID-19 patient. So it is necessary to continuously monitor D-dimer levels and labelled anticoagulation as management tools for COVID-19 disease to prevent complications and reduce interventions.

Keywords: Venous thrombotic events, D-Dimer, COVID -19

Corresponding Author

Manasa S, Microbiologist, Sagar hospital, Bangalore, Karnataka, India.

Email: manasabharadwaj86@gmail.com
How to Cite this Article

Manasa S, Vikram H C V. Analysis of D-Dimer Levels among Covid -19 Positive Patients in a Tertiary Care Hospital in Bangalore. Int J Med Res Rev. 2021;9(2):82-86.

Available From

https://ijmrr.medresearch.in/index.php/ijmrr/article/ view/1250
To Browse

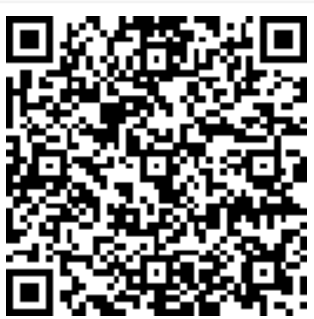

Manuscript Received 2021-02-10

Conflict of Interest No

(C) 2021 by Manasa S, Venkatesh Vikram. H. C and Published by Siddharth Health Research and Social Welfare Society. This is an Open Access article licensed under a Creative Commons Attribution 4.0 International License an Open Access article licensed under a Creative Commons Attribution 4.0 Internation
https://creativecommons.org/licenses/by/4.0/ unported [CC BY 4.0].
Review Round 3

Accepted

Review Round 2

2021-04-07

Ethical Approval

Yes
Plagiarism X-checker $4 \%$
2021-04-11

Note 


\section{Introduction}

Under normal physiological conditions, the hemostatic system maintains the balance between two opposing processes i.e

01. The coagulation process leads to the formation of thrombin, which converts fibre monomer molecules with the release of fibrinopeptides $A$ and $B$. These fibrin monomer molecules polymerize forming an insoluble fibrin network stabilized by covalent cross-links introduced by the action of the enzyme factor XIIIa, causing the formation of thrombus.

02. The fibrinolytic process leads to the lysis of the crosslinked fibrin by plasmin into a heterogeneous population of fragments released into the blood. These degradation products of cross-linked fibrinogen are called D-Dimer.

D-dimer is a degradation product of cross-linked fibrin resulting from plasmin cleavage. During fibrinolysis plasmin may degrade fibrin monomers, crosslinked fibrin polymers and possibly fibrinogen during systemic fibrinolysis following alpha2 depletion.

All these fragments are collectively called fibrin degradation products (FDPs). D-dimer constitutes two adjacent fibrin ' $D$ ' domains (ends) that are cross-linked and released as an intact fragment, hence the name $D$-dimer.

There are two main types of D-dimer assays, each reporting different $\mathrm{D}$-dimer units. The Fibrinogen Equivalent Unit (FEU) reports D-dimer levels based on the molecular weight of fibrinogen $(340 \mathrm{kDa})$, whereas the D-Dimer Unit (DDU) reports $D$-dimer levels based on its molecular weight (195kDa), which is about half that of fibrinogen.

Also, the reporting of the unit is different depending on the manufacturer, resulting in up to 9 different depictions of results, including $\mathrm{mg} / \mathrm{L}, \mathrm{mg} / \mathrm{dL}, \mathrm{ng} / \mathrm{dL}$, $\mathrm{ng} / \mathrm{mL}, \mu \mathrm{g} / \mathrm{L}, \mu \mathrm{g} / \mathrm{mL}, \mu \mathrm{g} / \mathrm{dL}, \mathrm{mg} / \mathrm{mL}$, and $\mathrm{ng} / \mathrm{L}$. In our hospital we used $\mu \mathrm{g} / \mathrm{L}$ to measure D-Dimer.

D-dimer is a product of cross-linked fibrin, it is considered a sensitive biomarker to rule out venous thromboembolism. However, D-dimer has low specificity as there are many other conditions with ongoing activation of the haemostatic system in which D-dimer can be elevated such as pregnancy, inflammation, malignancy, trauma, liver disease (decreased clearance), heart disease, sepsis or as a result of haemodialysis, or recent surgery.

\section{Materials and Methods}

Source of Data: This is a retrospective crosssectional study done for 6 months from July 2020 to December 2020. All the adult patients who were COVID-19 RT PCR positive were selected. The study was conducted in the Department of Microbiology, in a tertiary care hospital. The data regarding the DDimer levels were collected from the hospital software system.

Inclusion Criteria: All the adult patients who were RT PCR positive and were admitted to our hospital were included in the study.

\section{Exclusion Criteria:}

01. Presence of previous coagulative and liver disorders

02. Neonates and pediatric patients

03. Pregnant women

Were excluded from the study.

Methodology: We retrospectively reviewed all the adult patients who were COVID -19 RT PCR positive patients who were admitted to our hospital from July 2020 to December 2020. The data regarding the D-Dimer levels were collected from the hospital software system. Even the clinical data and patient outcome were also collected. Correlations of Ddimer upon admission, with disease severity and inhospital mortality were analyzed.

\section{Results}

The medical charts were reviewed for demographic (age, sex) data, clinical data of patients were also collected. Our records search showed that 1846 of the covid-19 RT PCR positive patients were admitted to our hospital from July 2020 to December 2020. The maximum number of patients were in the 50$60 y r s$ of age.

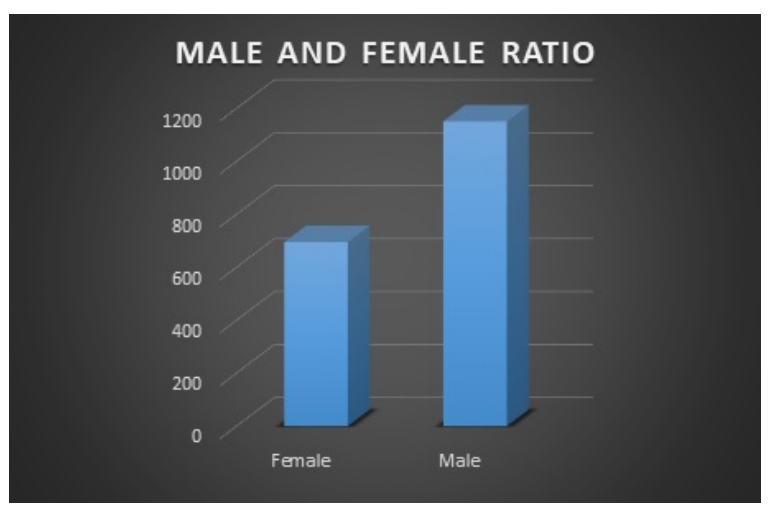


Fig 1: Male and female ratio of CovID-19 patients

In the total of 1846 COVID -19 patients 695 (37.6\%) were females and 1151 (62.4\%) were males. The D-dimer was tested on admission and also during treatment. The data was collected from the hospital software.

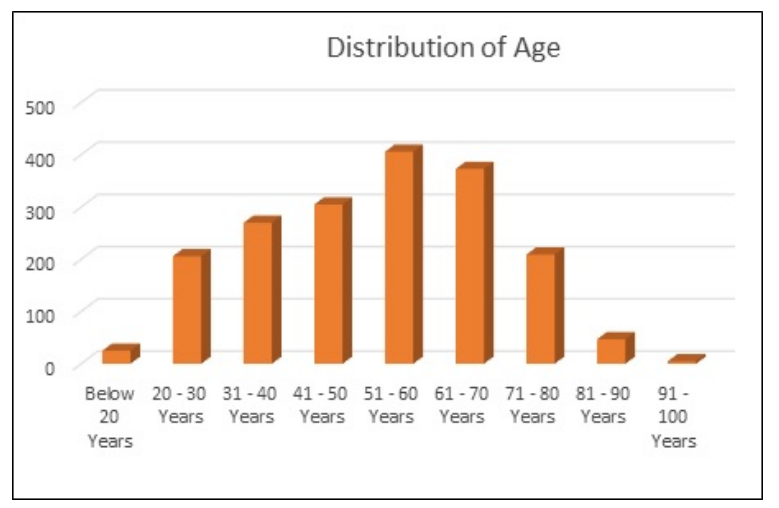

Fig 2: Age Distribution of COVID 19 patients

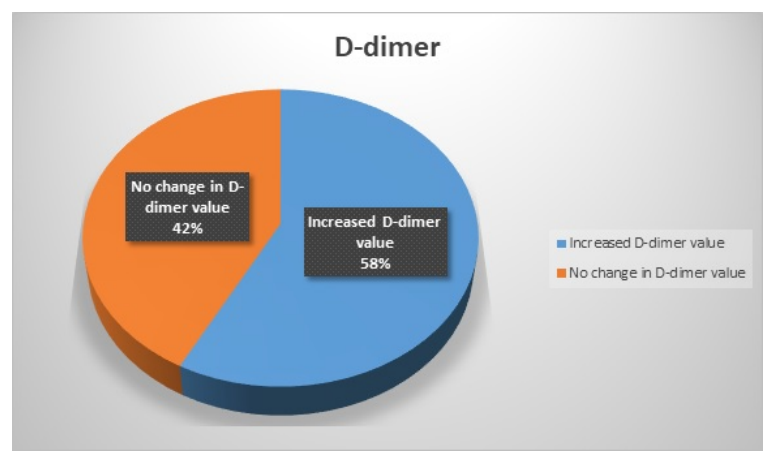

Fig 3: Comparison of $D$ dimer value during admission and course of treatment

Coagulation disorder occurred at the early stage of COVID-19 infection, with 1066 (57.7\%) patients having increased D-dimer levels. The levels of Ddimer were correlated with the clinical condition of the patient. Out of 1846 COVID 19 patients 106 (5.7\%)patients died due to complications.106 patients who deceased, all the patients had an increased $D$ dimer value either in the first lab test or in the consecutive tests. Among 106 patients $56(52.8 \%)$ patients had increased D-dimer at the first lab test, $32(30.1 \%)$ had D-dimer increased at the second and $18(16.98 \%)$ in third lab tests. Ddimer levels significantly increased with increasing severity of COVID-19 as determined by clinical staging. In addition, with the progression of the disease, the change of CT imaging was closely related to the increase of the $D$-dimer value $(P<0.01)$.
INCREASED D-DIMER LEVELS IN DECEASED PATIENTS

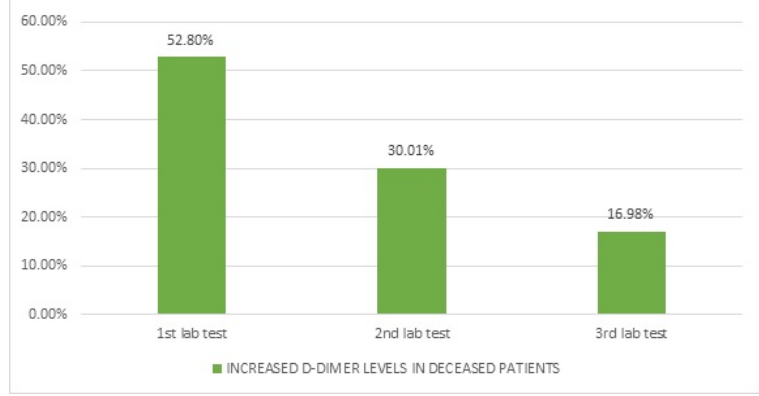

Fig 4: Increased D-dimer levels in the deceased patients

\section{Discussion}

Coagulation, the formation of a blood clot or thrombus, occurs when the proteins of the coagulation cascade are activated, either by contact with a damaged blood vessel wall and exposure to collagen in the tissue space (intrinsic pathway) or by activation of factor VII by tissue activating factors (extrinsic pathway). Both pathways lead to the generation of thrombin, an enzyme that turns the soluble blood protein fibrinogen into fibrin, which aggregates into protofibrils. Another thrombin-generated enzyme, factor XIII, then crosslinks the fibrin protofibrils at the $D$ fragment site, leading to the formation of an insoluble gel which serves as a scaffold for blood clot formation. [1]

The circulating enzyme plasmin, the main enzyme of fibrinolysis, cleaves the fibrin gel in several places. The resultant fragments, "high molecular weight polymers", are digested several times more by plasmin to lead to intermediate and then to small polymers (fibrin degradation products or FDPs). The cross-link between two D fragments remains intact, however, and these are exposed on the surface when the fibrin fragments are sufficiently digested. The structure of D-dimer is either a $180 \mathrm{kDa}$ or 195 $\mathrm{kDa}$ molecule of two D domains, or a $340 \mathrm{kDa}[6]$ molecule of two $D$ domains and one $E$ domain of the original fibrinogen molecule $[2,3]$

D-dimers are not normally present in human blood plasma, except when the coagulation system has been activated, for instance because of the presence of thrombosis or disseminated intravascular coagulation. The D-dimer assay depends on the binding of a monoclonal antibody to a particular epitope on the D-dimer fragment. Several detection kits are commercially available; all of them rely on a different monoclonal antibody against D-dimer. 
For some of these, the area of the D-dimer to which the antibody binds is known. The binding of the antibody is then measured quantitatively by one of the various laboratory methods. Upon SARS-CoV-2 entering the body through the angiotensinconverting enzyme 2 (ACE2) receptor adsorbed on the surface of mucosal epithelial cells $[4,5]$, its pathogen-associated molecular pattern (PAMP) can be quickly recognized by the immune system, and an immune response is activated to clear the virus. However, an over-activated immune response could cause a cytokine storm. As a result, cytokine storm causes vascular endothelial damage, activates the coagulation system, and inhibits the fibrinolytic and anticoagulating systems. Excessive thromboses in the microvascular system lead to disseminated intravascular coagulation (DIC) and, ultimately, microcirculatory disorder and serious multiple organ dysfunction syndromes [6]. Therefore, early detection and correction of coagulation dysfunction could effectively reduce mortality.

Commonly used laboratory coagulation indicators include DD, PT, APTT, and Fg. DD is the product of fibrinolytic solubilization of fibrin, and the elevated level of DD indicates that there is a hyper coagulating state and secondary fibrinolysis in the body, which can be seen in the increased fibrinolytic activity of the body system [7-10]. PT and APTT are exogenous and endogenous coagulating system factors, which can be used for early diagnosis of DIC. $\mathrm{Fg}$ is a protein with coagulation function synthesized by the liver, which is an important substance in the process of coagulation and thrombosis. A high level of $\mathrm{Fg}$ is an important indicator for a variety of thrombotic diseases. DD, PT, APTT, and $\mathrm{Fg}$ can be used as sensitive indicators to reflect different degrees of coagulating dysfunction. Therefore, in this article, the study was focused on if these indicators are related to the severity of COVID-19.

In our study Coagulation disorder occurred at the early stage of COVID-19 infection, with 1066 $(57.7 \%)$ patients having increased D-dimer levels. Out of 106 deceased patients all had increased D dimer levels in the 1st or consecutive $D$ dimer tests. They had severe pulmonary and extra-pulmonary complications of covid 19 which had lead to respiratory failure this is compared with $\mathrm{Y}$. Liu et al where it has been reported that about $50 \%$ of the patients had increased D-dimer levels, and abnormal D-dimer levels are associated with poor prognosis $[11,12]$.
Thus, in some stable patients with sudden death, acute organ and embolism and infarction should take into consideration. Although the incidence of thrombosis in patients with COVID-19 has not been determined, the incidence of deep vein thrombosis (DVT) and pulmonary embolism (PE) was $20.5 \%$ and $11.4 \%$ respectively in SARS cases [13]. Also, thromboembolisms formation was seen in pathological studies based on autopsies or biopsies, which greatly resemble those seen in SARS and MERS coronavirus infection $[14,15]$.

\section{Conclusion}

High elevation of D-dimer levels increase the rate of complications. The appropriateness of early and continuous D-dimer monitoring and labelled anticoagulation as management tools for COVID-19 disease deserves accurate investigation, to prevent complications and reduce interventions.

\section{Author contribution}

Manasa S: Compelling and analysing the data, Venkatesh Vikram H C: Data collection.

\section{What does this study add to existing knowledge?}

Continuous monitoring of D-dimer levels and labelled anticoagulation can be used as management tools for COVID-19 disease to prevent complications and reduce interventions

\section{Reference}

01. Adam SS, Key NS, Greenberg CS. D-dimer antigen- current concepts and prospects". Blood. 2009;113(13)2878-87.

doi:10.1182/blood-2008-06-165845

[Crossref]

02. Kogan $A E$, Mukharyamova $K S$, Bereznikova AV, Filatov VL, Koshkina EV, Bloshchitsyna MN, Katrukha AG. Monoclonal antibodies with equal specificity to D-dimer and high-molecularweight fibrin degradation products". Blood Coagulation \& Fibrinolysis. 2016;27(5)542-50. doi: $10.1097 / M B C .0000000000000453$ [Crossref]

03. Olson JD, Cunningham MT, Higgins RA, Eby CS, Brandt JT. D-dimer- simple test, tough problems. Archives of Pathology \& Laboratory Medicine. 2013;137(8)1030-8.

doi: $\quad 10.5858 /$ arpa.2012-0296-CP [Crossref] 
04. Wan Y, Shang J, Graham R, Baric RS, Li F. Receptor Recognition by the Novel Coronavirus from Wuhan- an Analysis Based on Decade-Long Structural Studies of SARS Coronavirus. J Virol. 2020 Mar 17;94(7)e00127-20.

doi: $10.1128 /$ JVI.00127-20 [Crossref]

05. Kowalczuk S, Bröer A, Tietze N, Vanslambrouck JM, Rasko JE, Bröer S. A protein complex in the brush-border membrane explains a Hartnup disorder allele. FASEB J. 2008 Aug;22(8)28807.

doi: $10.1096 /$ fj.08-107300 [Crossref]

06. Cohen J. The immunopathogenesis of sepsis. Nature. 2002 Dec 19-26;420(6917)885-91.

doi: $10.1038 /$ nature01326 [Crossref]

07. Giannitsis E, Mair J, Christersson C, Siegbahn A, Huber K, Jaffe AS, Peacock WF, Plebani M, Thygesen K, Möckel M, Mueller C, Lindahl B. Biomarker Study Group of the European Society of Cardiology (ESC) Acute Cardiovascular Care Association (ACCA)- How to use D-dimer in acute cardiovascular care. Eur Heart J Acute Cardiovasc Care. 2017 Feb;6(1)69-80.

doi: $10.1177 / 2048872615610870 \quad$ [Crossref]

08. Ramana CV, DeBerge MP, Kumar A, Alia CS, Durbin JE, Enelow RI. Inflammatory impact of IFN- $Y$ in $\mathrm{CD} 8+\mathrm{T}$ cell-mediated lung injury is mediated by both Stat1-dependent andindependent pathways. Am J Physiol Lung Cell Mol Physiol. 2015 Apr 1;308(7)L650-7.

doi: 10.1152/ajplung.00360.2014 [Crossref]

09. Behrens K, Alexander WS. Cytokine control of megakaryopoiesis. Growth Factors. 2018 Aug;36(3-4)89-103.

doi: 10.1080/08977194.2018.1498487 [Crossref]
10. Liu Y, Gayle AA, Wilder-Smith A, Rocklöv J. The reproductive number of COVID-19 is higher compared to SARS coronavirus. J Travel Med. 2020 Mar 13;27(2)taaa021.

doi: 10.1093/jtm/taaa021 [Crossref]

11. Guan WJ, Ni ZY, $\mathrm{Hu} Y$, et al. Clinical Characteristics of Coronavirus Disease 2019 in China. N Engl J Med. 2020;382(18)1708-1720. doi: 10.1056/NEJMoa2002032 [Crossref]

12. Tang N, Li D, Wang X, Sun Z. Abnormal coagulation parameters are associated with poor prognosis in patients with novel coronavirus pneumonia. J Thromb Haemost. $2020 ; 18(4) 844-847$. doi: $10.1111 /$ jth. 14768 [Crossref]

13. Chong PY, Chui $P$, Ling AE, et al. Analysis of deaths during the severe acute respiratory syndrome (SARS) epidemic in Singaporechallenges in determining a SARS diagnosis. Arch Pathol Lab Med. 2004;128(2)195-204.

[Crossref]

14. Xu Z, Shi L, Wang Y, et al. Pathological findings of COVID-19 associated with acute respiratory distress syndrome. Lancet Respir Med. $2020 ; 8(4) 420-422$.

doi: $10.1016 / S 2213-2600(20) 30076-X \quad$ [Crossref]

15. Lang Z, Zhang L, Zhang S, Meng X, Li J, Song C, Sun L, Zhou Y. Pathological study on severe acute respiratory syndrome. Chin Med J Peking. 2003;07;17-21.

[Crossref] 